\title{
Development Sensor Experimental Platform Based on the Graphical Monitoring and Control System
}

\author{
Wen-Jye Shyr \\ Department of Industrial Education and Technology \\ National Changhua University of Education \\ Taiwan, R.O.C.
}

\section{Introduction}

Sensors have traditionally been used for industrial process control, measurement, and automation, often involving light, temperature, pressure, flow, and level measurement (Ramon and John, 2001). Harsanyi and Lepsenyi (2000) surveyed research work the sensor's laboratory. Results originate from student work at different levels, ranging from undergraduate to Ph.D. Individual areas are under research and development, and results demonstrated here are not always complete.

Ahmad (1988) reported a laboratory experiment to teach concepts of sensor-based robot assembly systems. These sensor-based motion strategies improve robot assembly system reliability. This article discusses the sensor-based assembly experiment, the laboratory setup, and the sensor-based motion strategies in detail. Peyton et al. (1996) take the view that principles of sensor operation and instrumentation are important subjects for an electronics/mechatronics undergraduate course and should be presented as early as possible within the overall degree program.

This chapter addresses an experimental sensor module based on the graphical monitoring and control system. First, this system gleans and sorts different data, then integrates the experimental sensor module via student-created projects. Second, this system edits graphical monitoring and control system software. Finally, it connects the software with the hardware of different optoelectronic devices to achieve a sensor module based on the graphical monitoring and control system. This article also develops experimental instruction material to offer practical graphical monitoring and control system experience to students involved in a team project.

The remainder of this chapter is organized as follows. Section 2 describes sensors. Section 3 gives the graphical monitoring and control system overview. Section 4 presents experimental descriptions of several different sensor modules. The project experiment is shown in Section 5. The evaluation is shown in Section 6. Section 7 offers conclusions. 


\section{Sensor Description}

A complete instruction material in sensor and graphical monitoring and control system fundamentals is an introduction to control. With this system, students can explore the principles and applications of different sensor devices, all commonly found in industry. The most common sensor types are the photo-resistor and temperature-sensor.

The most common types of photo-sensors are the photo-resistor, the phototransistor, the solar cell, and the fiber-optical sensor. The photo-sensor devices form a specialized branch of the semiconductor technology. These photo-sensor devices find application in a variety of measurement and control systems such as: (1)Light level measurement, (2)Optical switching, (3)Non-contact switching, (4)Shaft encoders, (5)Position readers, (6)Remote control, (7)Paper handlers, (8)Coin handlers, (9)General purpose interruptive sensing, (10)Logic circuits, and (11)Counting systems.

Temperature sensors are often used within electronic systems to monitor temperature and provide protection from excessive temperature excursions. The most common temperature sensors a system uses are listed as follows: thermocouple, RTD, thermistor and AD590.

\subsection{Photo-resistor (CDS, Cadmium Sulfide)}

The resistor is one of the most common electronic components. A resistor is a device that limits, or resists current. The current limiting ability or resistance is measured in ohms, represented by the Greek symbol Omega $(\Omega)$.

The photo-resistor does not have a specific fixed resistance. Resistance is based on the amount of light that falls on it. The photo-resistor is basically a chunk of silicon crystal with a lead on each end exposed to the light. Resistance is very high in the absence of light. Resistance falls dramatically, often to several hundred ohms when the resistor illuminates. The photo-resistor may also be called CDS (Cadmium Sulfide) cells. Important aspects of the photo-resistor operation include: (1)The photo-resistor may require a few milliseconds or more to fully respond to changing light intensity. It may require many minutes to return to its normal dark resistance when light is removed. (2)The semiconductor most often used in the photo-resistor is cadmium sulfide, and its light sensitivity is very similar to that of the human eye! The light sensitive semiconductor is typically coated between interleaved electrodes to increase its exposed surface. A plastic or glass window may or may not be used. Photo-resistors are commonly used in light controlled relays and light meters.

\subsection{Phototransistor}

The transistor is basically a semiconductor switch or amplifier. In the case of an NPN transistor, a small current applied to the base allows a much larger current to flow from the collector to the emitter. The transistor functions as a switch when the maximum amount of base current is applied to the transistor and saturates it. Smaller amounts of current applied to the base change the transistor's output changes. Photons entering the base replace the base-emitter current of ordinary NPN transistors. Therefore, a phototransistor directly amplifies variations in the number of photons. The phototransistor is often used to detect fluctuating light signals. This acts like any other base and also affects current flow through the transistor. Phototransistors are most sensitive to light, but also respond to regular light. They are used in receivers, light sensors, etc. The collector is the one angled line without the arrow. The emitter is the angled line with the arrow pointing down away from the straight 
line. Light-sensitivity of the device is represented by downward arrows. Phototransistors may or may not be drawn with the circle surrounding them.

\subsection{Solar Cell}

A solar cell is a PN junction photodiode with a large light sensitive area. Light striking the cell causes electrons to flow. Several solar cells may be connected in series or parallel to form a solar panel. If they're connected in series, the output voltage is the sum of voltages for each solar cell. When they're connected in parallel, the output current is the sum of currents for each solar cell. Arrows pointing at the cell on the schematic represent light. Photodiodes are diodes that generate electricity when illuminated. A diode is a component that only allows electricity to flow one way, a kind of one-way street for electrons.

Silicon photovoltaic cells are typically considered as voltage supplies, but are also useful as sensitive detectors of light and near infrared. Solar cells are silicon wafers doped to produce a p-n junction. Commonly used "cells" are produced as wafers with a diameter of about $8 \mathrm{~cm}$ and $3 \mathrm{~mm}$ thickness, cut from a crystalline silicon rod. The thin wafer is doped on one side to produce p-material (e.g., boron doped silicon) and on the other side to produce n-material (e.g., phosphorous doped silicon). The p material is typically connected to a metal base and the topside of the wafer (n-type) has an electrical contact grid. Light striking the top of the wafer penetrates through the p-n junctions and free electrons, crossing the junction into the n-type region. Electrons are then held in the n-region, unable to re-cross the junction into the p-region. Figure 4 shows the solar cell symbol and transducers used for a light detector.

\subsection{Fiber-optic Sensor}

A fiber optic sensor is a sensor that uses an optical fiber, either as the sensing element, or for relaying signals from a remote sensor to the electronics that process the signals. Fibers have many uses in remote sensing. Depending on the application, a fiber may be used due to its small size, or because the remote location does not need electrical power, or because many sensors can be multiplexed along the fiber length, using different light wavelengths for each sensor. Fiber optics sensing is the latest emerging technology that plays a key role in monitoring large structures using only one continuous sensor, the fiber optic line itself. This technology translates into a cost reduction alternative compared to other measuring techniques and technologies requiring hundreds of sensors to cover the same area.

Fiber optic sensor characteristics are as follows: (1)Compact design, water and corrosion resistant;(2)Immune to electromagnetic interferences; (3)Passive operation (no electrical signal); (4)The fiber is both the transducer and the signal transmission medium; (5)Measurement signal insensitive to intensity losses over the fiber (transmission over distances up to several kilometers); (6)No calibration required; (7)Ability to multiplex dozens or more sensors on a single optical fiber (parallel and serial multiplexing); (8)Long lifetime.

\subsection{Thermocouple}

The thermocouple uses the see-back effect. This is where two dissimilar metal alloys produce an Electro-Motive Force (EMF is a fancy way of saying "voltage") nearly proportional to temperature. Thermocouples are made by joining two wires of dissimilar 
metals. Thermocouple types differ by metallic composition and are designated by a single letter such as J, T, or K. Temperature can be calculated by knowing the thermocouple type. The contact point between the wires generates a voltage approximately proportional to temperature. Characteristics include wide temperature range, low-cost, very low output voltage, reasonable linearity, and moderately complex signal conditioning (cold-junction compensation and amplification). Thermocouples are available in probes and with bare leads.

Thermocouple voltage output means the temperature is not a linear relationship; however it may be approximated as one. This voltage amplifies by signal conditioning equipment and then inputs to the computer through the DAQ card, thus turning a real life temperature measurement into a digital value on a computer that can be analyzed and presented. Figure 6 shows the thermocouple symbol and transducers used for temperature detection.

\subsection{RTD (Resistive Temperature Detector)}

The resistive temperature detector is made of coils or films of metals (usually platinum). When heated, metal resistance increases; when cooled, resistance decreases. Measuring this voltage determines its resistance, and thus its temperature. Resistance temperature detector, or RTD, is a highly accurate temperature sensor, known for its excellent stability characteristics.

RTD characteristics include wide temperature range, excellent accuracy and repeatability, reasonable linearity, and the need for signal conditioning. Signal conditioning for an RTD usually consists of a precision current source and a high-resolution ADC circuit. RTDs are available in probes, in surface-mount packages, and with bare leads. RTD lead resistances require care, due to their low resistance values. The resistance/temperature curve for a $100 \Omega$ platinum RTD, is commonly referred to as Pt100.

\subsection{Thermistor}

The thermistor is a temperature-dependent resistor, typically molded from conductive materials. The most common thermistor has a negative temperature coefficient (NTC) of resistance. Thermistor characteristics include a moderate temperature range, low-to-moderate cost (depending on accuracy), poor but predictable linearity, and the need for some signal conditioning. The thermistor is available in probes, in surface-mount packages, with bare leads, and in a variety of specialized packages. Maxim manufactures ICs that convert thermistor resistance to digital form.

Like RTD, it reads voltage across the thermistor and thus determines its temperature. Unlike RTD, the thermistor has a higher resistance (anywhere from $2 \mathrm{~K} \Omega$ to $10 \mathrm{~K} \Omega$ ) and a much higher sensitivity. However, the thermistor is generally only used up to the $300^{\circ} \mathrm{C}$ temperature range. Due to thermistor high resistance, lead-wire resistance does not affect measurement accuracy, unlike RTD. The 2-wire measurement is generally adequate.

The thermistor has either a negative temperature coefficient (NTC) or a positive temperature coefficient (PTC). The first has a resistance, which decreases with increasing temperature and the latter exhibits increased resistance with increasing temperature. Figure 8 shows the thermistor symbol and transducers used for temperature detection. 


\subsection{AD590}

The AD590 is an integrated-circuit temperature transducer, which produces an output current proportional to absolute temperature. The device acts as a high impedance constant current regulator, passing $1 \mu \mathrm{A} /{ }^{\circ} \mathrm{K}$ for supply voltages between $+4 \mathrm{~V}$ and $+30 \mathrm{~V}$. Laser trimming of the chip's thin film resistors calibrates the device to $298.2 \mu \mathrm{A}$ output at $298.2^{\circ} \mathrm{K}$ $\left(25^{\circ} \mathrm{C}\right)$.

The AD590 should be used in any temperature-sensing application between $-55^{\circ} \mathrm{C}$ to $150^{\circ} \mathrm{C}$ that employs conventional electrical temperature sensors. The inherent low cost of a monolithic integrated circuit combined with support circuitry elimination makes the AD590 an attractive alternative for many temperature measurement situations. Linearization circuitry, precision voltage amplifiers, resistance measuring circuitry and cold junction compensation are not needed in applying the AD590. In the simplest application, a resistor, a power source and any voltmeter can be used to measure temperature. In addition to temperature measurement, applications include temperature compensation or correction of discrete components, and biasing proportional to absolute temperature.

The AD590 is particularly useful in remote sensing applications. The device is insensitive to voltage drops over long lines due to its high-impedance current output. Any well-insulated twisted pair is sufficient for operating hundreds of feet from the receiving circuitry. Output characteristics also make the AD590 easy to multiplex: the current can be switched by a CMOS multiplexer or the supply voltage can be switched by a logic gate output. The AD590 features include: (1) Linear current output $1 \mu \mathrm{A} /{ }^{\circ} \mathrm{K}$, (2) Wide temperature range $-55^{\circ} \mathrm{C}$ to $150^{\circ} \mathrm{C}$, (3) Two-terminal device voltage in/current out, (4)Wide power supply range $+4 \mathrm{~V}$ to $+30 \mathrm{~V}$, (5)Sensor isolation from case, (6)Low cost.

\section{Graphical Monitoring and Control System}

This section describes graphical monitoring and control system requirements for the experimental sensor module.

\subsection{General Description}

(1)Work under this section includes providing graphical monitoring and control system equipment to provide the following functionality: (i) Monitoring sensor status, (ii) Gathering and storing sensor information, and (iii) Detailed analysis and trouble-shooting of the sensor system.

(2)An existing personal computer workstation stores collected data, system operation and analytical software.

(3)Sensor information should be transmitted to and integrated into the building sensor experimental module based on the graphical monitoring and control system.

\subsection{System Description}

(1)The existing system includes the experimental sensor module for graphical monitoring and control, device interface hardware, inter-communication wiring, a personal computer workstation, software, interfacing, printer, and ancillary equipment.

(2)The existing system utilizes the high-speed backbone network. 
(3)A personal computer workstation connected to the network has equal access to information provided by graphical monitoring devices for centralizing data display, data logging, alarming, event recording, and other monitoring operations.

(4)The high-speed network allows direct access to data provided by graphical monitoring devices for implementing different automatic sensor controls.

\section{Experiment Description}

The system mainly implements the experimental sensor module based on the graphical monitoring and control system in laboratory sessions. Figure 1 illustrates this system. This study asserts that the time students take to participate in "active learning" such as experiments, is as important as "passive learning" through attending lectures. The same features result from some experiment or practice-oriented systems (Halang, 1990; Sloane, 1995).

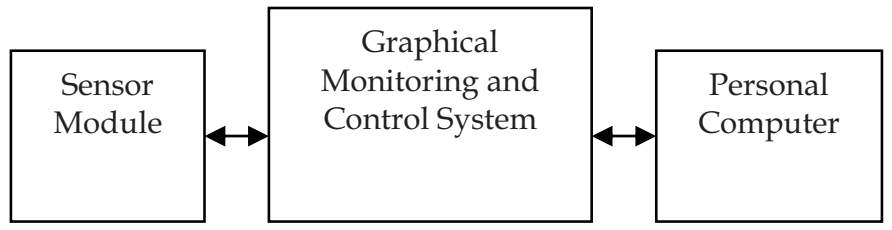

Fig. 1. Sensor experimental module based on the graphical monitoring and control system

\subsection{Photo-resistor (CDS) Sensor Module}

A photo-resistor is an electronic component whose resistance decreases with increasing incident light intensity. The photo-resistor can also be called a light-dependent resistor (LDR), or photoconductor. It is made of a high resistance (A substance such as germanium or silicon with intermediate electrical conductivity between that of metal or an insulator; its conductivity increases with temperature and in the presence of impurities) semiconductor. High frequency light falling on the device enables photons absorbed by the semiconductor to give bound electrons enough energy to jump into the conduction band. The resulting free electron and its hole-partner conduct electricity, thereby lowering resistance. Without getting into a lot of boring theory, the students connect a CDS to them and run it to the module.

Figure 2 shows the basic photo-resistor circuit. The circuit gives an output voltage that increases with higher-level light. Figure 3 shows the photo-resistor (CDS) sensor module. 


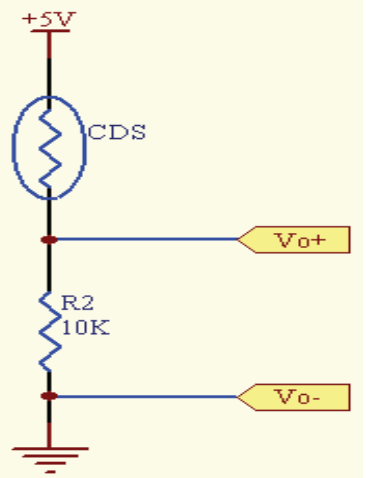

Fig. 2. The basic photo-resistor (CDS) circuit

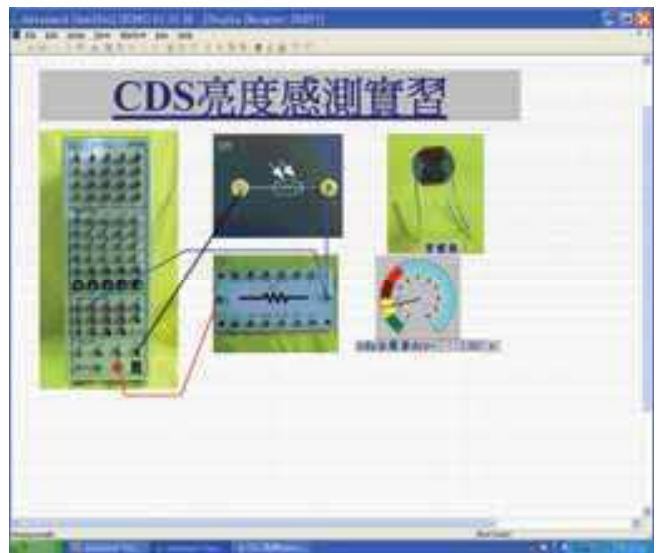

Fig. 3. The photo-resistor (CDS) sensor module

\subsection{Phototransistor Sensor Module}

Actual operation of a phototransistor depends on the biasing arrangement and light frequency. For instance, if a PN junction is forward biased, the increased current through the junctions due to incident light will be relatively insignificant. On the other hand, if the same junction is reverse biased, the increase in current flow will be considerable and is a light intensity function. If the p-n junction is the collector-base diode of a bipolar transistor, the light-induced current effectively replaces the base current. The physical base lead of the transistor can be left as an open terminal, or it can be used to bias up to a steady state level. A change in the base current in transistors can cause a significant change in collector current. Thus, light stimulation causes a change in base current, which in turn causes a bigger increase in the collector current, resulting in a rather large increase, considering the current gain.

The following schematic shows the basic phototransistor circuit in Figure 4. The circuit gives an output voltage that increases with higher light level. Figure 5 shows the phototransistor sensor module. 


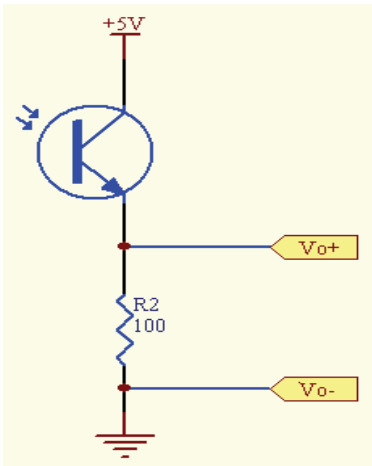

Fig. 4. The basic photo-transistor circuit

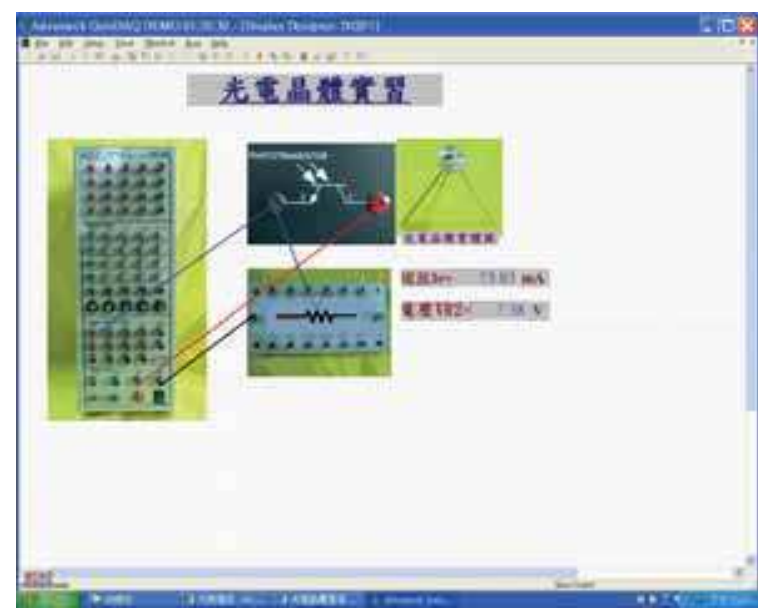

Fig. 5. The phototransistor sensor module

\subsection{Solar Cell Sensor Module}

Solar cell power is generated using the photovoltaic effect of semiconductors. A semiconductor exposed to a light source of suitable intensity, generates a large number of electron pairs and a positive hole, resulting from reciprocal action between photons and silicon atoms.

At a p-n junction between two different semiconductor materials, the electrons diffuse in the n-type material and scatter the positive holes in the p-type material. They are then collected at both electrodes respectively, resulting in a voltage difference between the electrodes. When an external load is connected, electricity flows through the load. In this way, a silicon solar cell converts light energy into electricity and supplies power to external loads.

Figure 6 shows the basic solar cell circuit. The circuit gives an output voltage that increases with higher light levels. Figure 7 shows the solar cell sensor module. 


\subsection{Fiber-Optic Sensor}

A measurement system based on a fiber-optic sensor consists of a light source (LED or laser), an optical fiber, and a photo-detector. LED (infrared or visible) are highly reliable and easy to integrate in the system but have low coupling efficiency. Common photo-detectors in fiber-optic sensors are phototransistors, and photodiodes.

Figure 8 shows the fiber-optic sensor circuit. The circuit gives high/low output voltage according to the $1 \mathrm{~Hz}$ square wave. The output voltage is high, when the square wave is low. The output voltage is low, when the square wave is high. Figure 9 shows the solar cell sensor module.

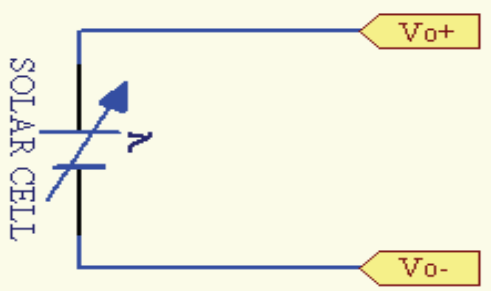

Fig. 6. The basic solar cell circuit

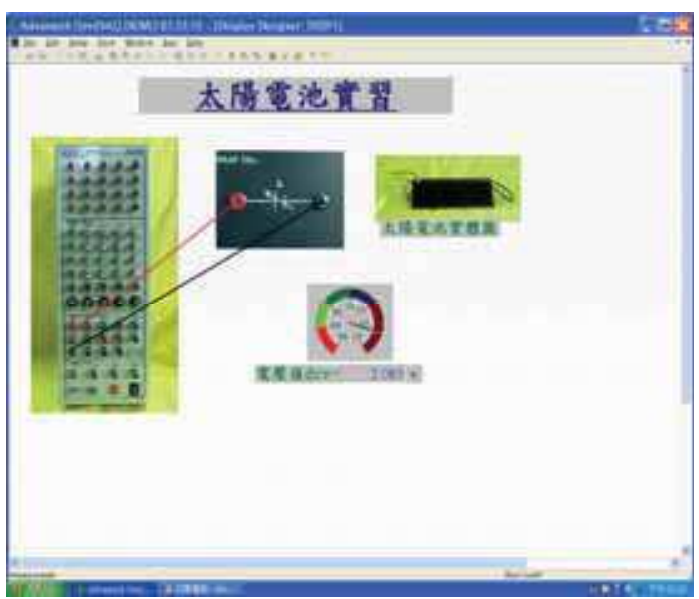

Fig. 7. The solar cell sensor module 


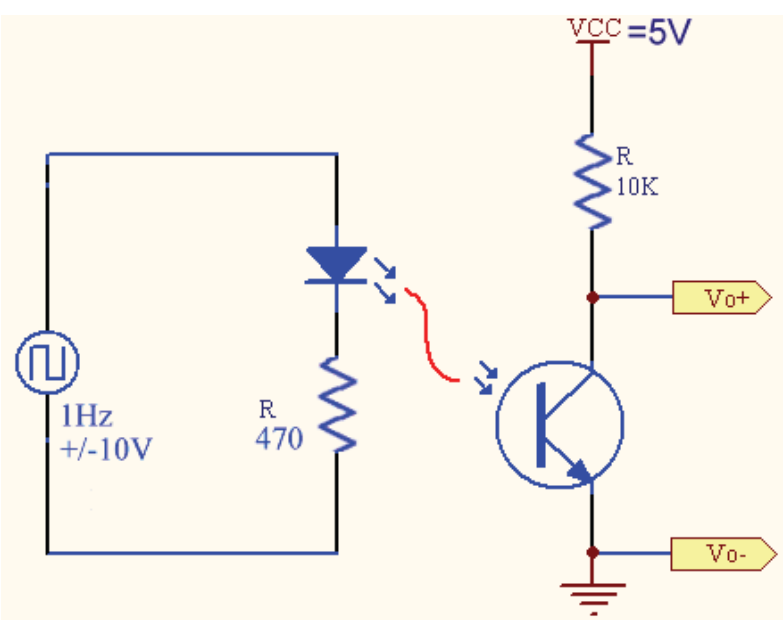

Fig. 8. The fiber-optic sensor circuit

Fig. 9. The fiber-optic sensor module

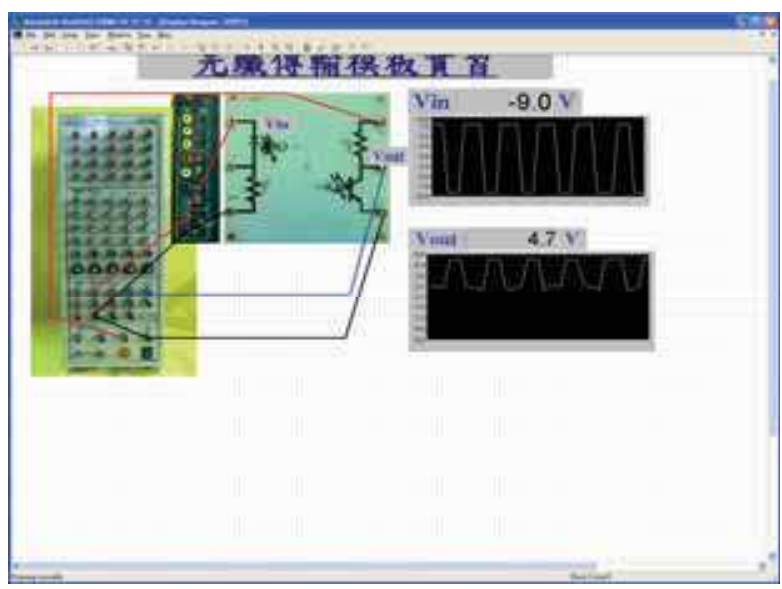

\subsection{Thermocouple Sensor Module}

Figure 10 shows the basic thermocouple circuit. The thermocouple sensor module is shown in Figure 11.The problem with the thermocouple is that students connecting a pair of copper wires to the thermocouple and running it to the module create three dissimilar metal junctions, which introduce measurement errors. Also, a second junction at a known temperature is required for useful thermocouple temperature sensor measurements. Previous experiments used an ice bath in the lab for the cold junction. Many DCV have a built-in cold junction for thermocouple temperature measurements that only require hooking up the proper thermocouple and setting the DCV to temperature.

Any lab rat can make two mistakes when hooking up a thermocouple: hook them up backwards, or use the wrong type of thermocouple. Either way might give a believable but 
incorrect reading, which is reason enough to avoid using thermocouples for critical experiments.

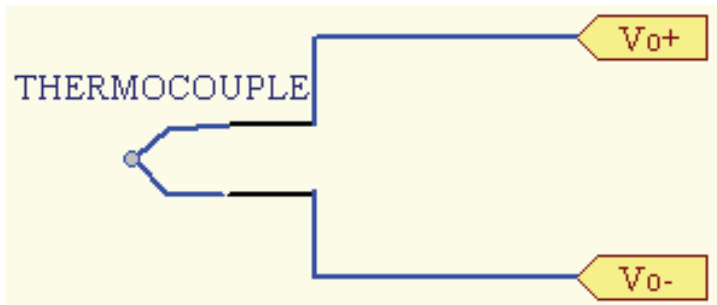

Fig. 10. The basic thermocouple circuit

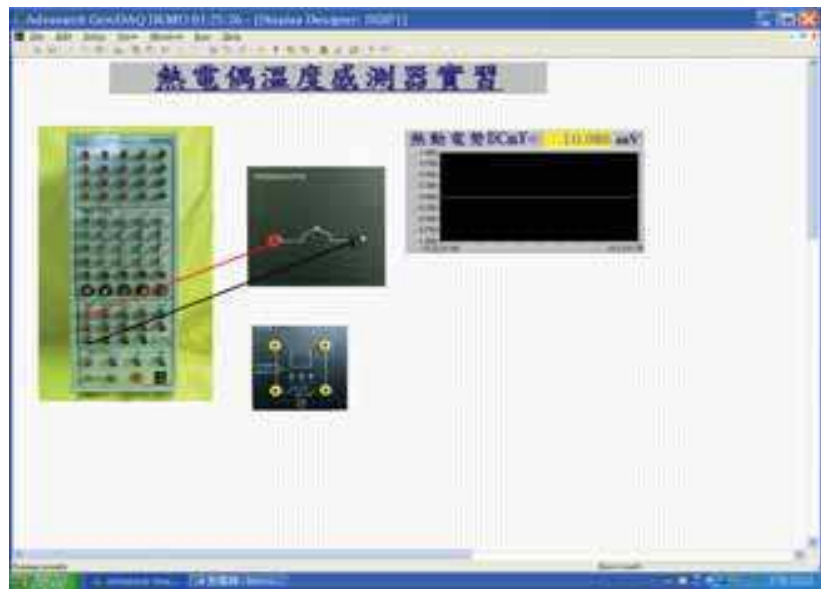

Fig. 11. Thermocouple sensor module

\subsection{RTD Sensor Module}

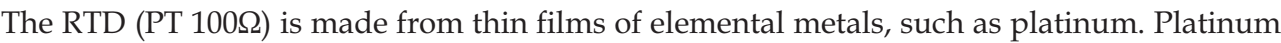
has very low bulk resistivity, necessitating a thin film with a lot of squares to obtain a useful total resistance. The temperature coefficient of resistance (TCR) of platinum RTD is around $0.0038 \Omega /{ }^{\circ} \mathrm{C}$. Figure 12 shows the basic RTD circuit. Figure 13 shows the RTD sensor module is shown.

\subsection{Thermistor Sensor Module}

Figure 14 shows a typical thermistor circuit is. Figure 15 shows the thermistor sensor module. The therrmistor consists of resistors (or perhaps semiconductors) that have predictable negative temperature coefficients. The temperature coefficients are abbreviated NTC (negative). The thermistor is typically made of some type of ceramic.

The thermistor resistance/temperature function is not as linear as an RTD, but much cheaper. Choosing a thermistor or RTD means accounting for self-heating of the device due to the current passing through it to obtain a voltage reading. 


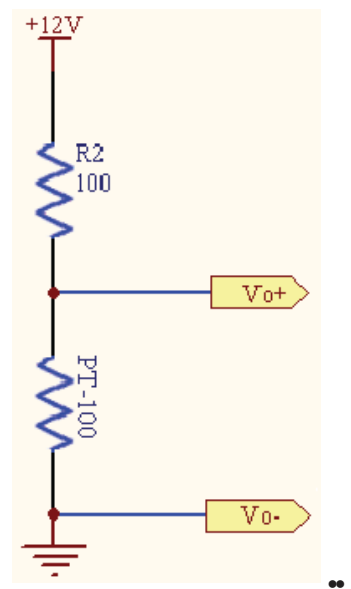

Fig. 12. The basic RTD (PT100) circuit

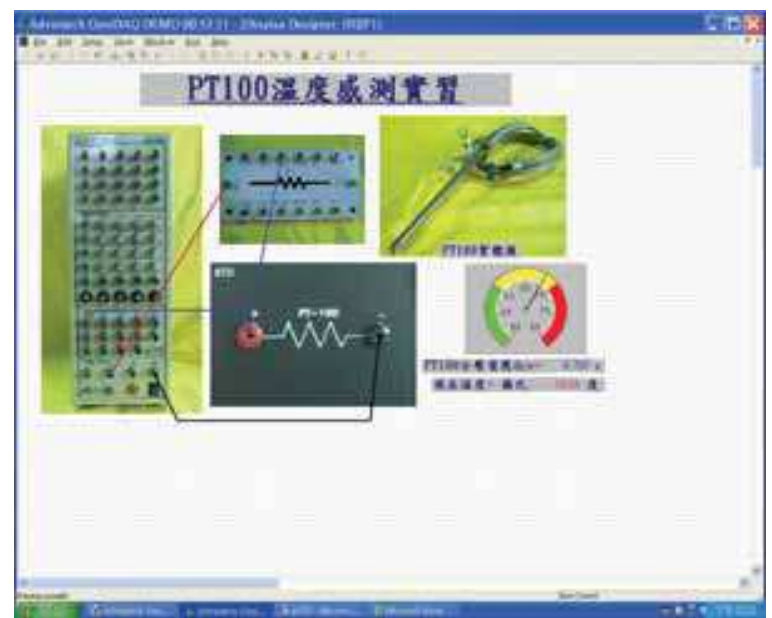

Fig. 13. RTD (PT100) sensor module 


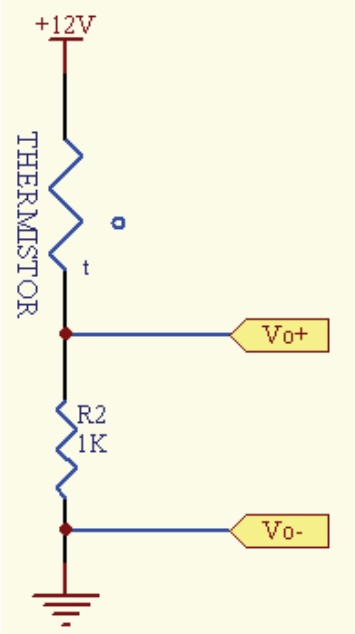

Fig. 14. A typical thermistor circuit

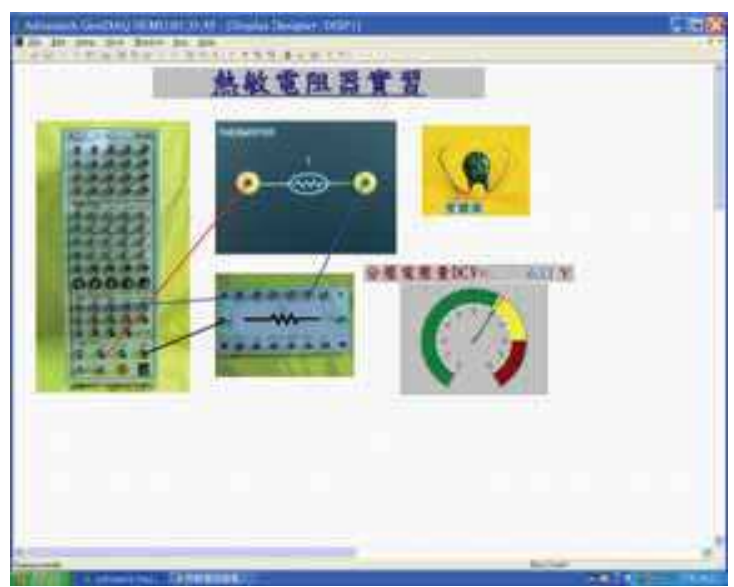

Fig. 15. Thermistor sensor module

\subsection{AD590 Sensor Module}

Figure 16 shows a typical thermistor circuit. Figure 17 shows the AD590 sensor module. This part provides a current in $\mu \mathrm{A}$ that is nearly equal to its temperature in degrees Kelvin. This type of sensor is far less prone to errors due to lead resistance than a voltage sensor, thermistor or RTD. 


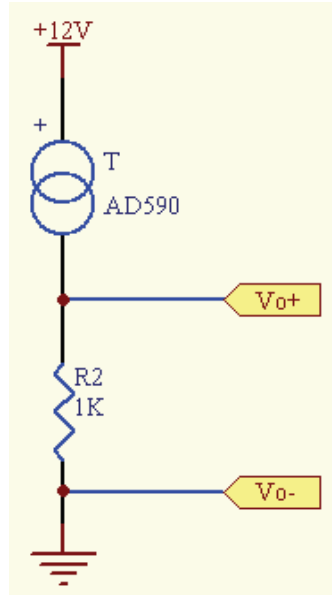

Fig. 16. The AD590 circuit

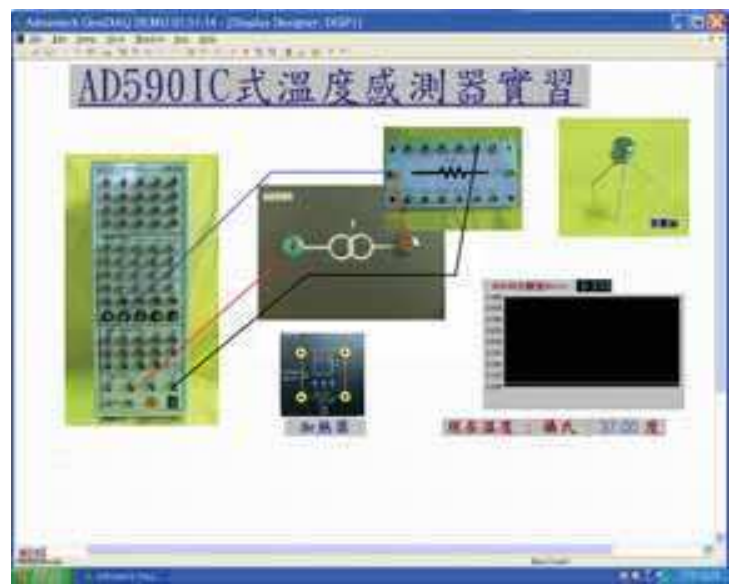

Fig. 17. AD590 sensor module

\section{Project Experiment}

The most important part of the system implements the temperature-sensing module based on the graphical monitoring and control system used in laboratory projects.

Figure 18 designs a comprehensive temperature monitoring and control system. Every measurement point has a thermocouple connected to an analog input module, along with a relay output module. All modules connect to the host computer through an RS-485 twisted pair interface. An independent power source supplies the analog input modules and every digital alarm output connects to an independent system of sirens and alarm lights, which guarantees efficiency even during computer system failures. The analog input module reads the thermocouple voltage and converts it into temperature, which is then sent to the host. The graphical human interface temperature control system displays the temperature and 
constantly checks it. When the temperature rises above a preset limit, the system orders the relay output module to turn on the air conditioning in that specific area. When the temperature returns to the set point, the system orders the relay module to turn the air conditioning off.

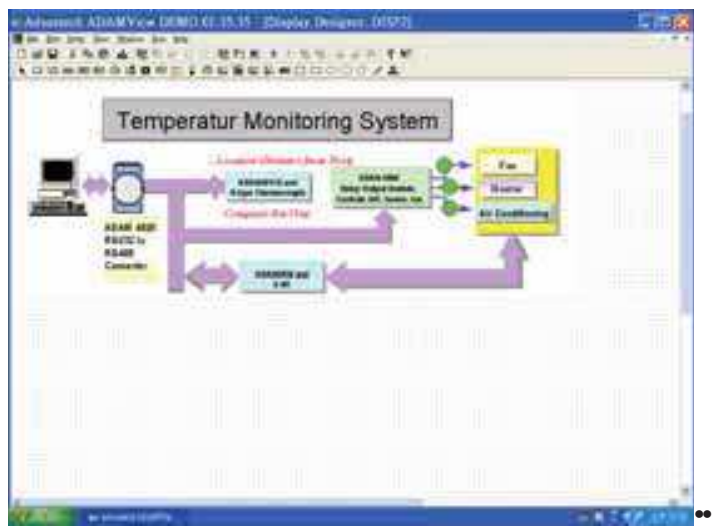

Fig. 18. Temperature monitoring system

\section{Evaluation}

This study utilizes learning evaluation to increase standards in terms of teaching, learning and student achievement. Evaluation quality has a marked impact on student willingness to work hard and encourages teachers to focus on ways to improve individual learning attitudes. Evaluation occurs continually as students judge themselves and others (Wong, et al., 2005). User evaluation is a domain that is not as well articulated and explored as assessing whether a system is usable, or whether it actively increases work productivity (Isbister, et al., 2007).

Student surveys administered at the end of the semester, asked students to evaluate the experimental module. Students generally responded very positively to the lecture and the laboratory work. Based on literature review and referring to related researches and questionnaires, this article drew up a laboratory activity evaluation questionnaire. Ten experts reviewed the first draft of the questionnaire, after which it was modified and finally finished.

The experts were university professors and/or researchers, averaging more than three years of experience in sensor teaching and with a good knowledge of the graphical human interface system. Overall, the expert evaluations were generally positive.

This innovative experimental and teaching method was inaugurated at the Department of Industrial Education and Technology at National Changhua University of Education. Twenty students completed the system in 2007. The students offered many positive comments in their evaluations of the instruction. They communicated that they learned more effectively using practice-oriented sensors, and the graphical monitoring human interface technology-based system. For example, they very much liked avoiding low-level implementation issues and felt that the course and laboratory synchronized with each other. They appreciated the laboratory lectures and felt that they helped show how they could 
apply the methods to other sensor applications. The negative responses concerned the amount of time required for the design project at a time when the demands of other courses were also high at the end of the semester. The students suggested that the design project be assigned earlier in the semester to solve this problem.

Overall, the students responded that this system provided a unique and valuable learning experience. Students who completed this system felt satisfaction and accomplishment because they actually designed and constructed an experimental sensing module based on the graphical human interface system. The author has created a laboratory manual for the experimental sensing module that includes laboratory assignments and discusses necessary details of how to complete the laboratory tasks.

\section{Conclusions}

This chapter addresses the development of an experimental sensor module based on the graphical monitoring and control system. Several different sensors are available for the graphical monitoring and control system. This system emphasizes both theory and practice and the sequence covers general sensor physics and technology as well as new and novel state of the art sensor design. This system will hopefully bridge the gap between university education and industrial applications. The innovative experiment and teaching methods have been inaugurated in the department of industrial education and technology at National Changhua University of Education. Students work on a design project to test and integrate an actual sensor device. The goal of the system sequence is to use the research and facilities in smart sensor development to give students a comprehensive background in the art and science of sensor and device technology, design, and integration.

\section{References}

Ahmad, S. (1988). A laboratory experiment to teach some concepts on sensor-based robot assembly systems. IEEE Transactions on Education 31(2): 74-84.

Halang, W. A., 1990. A curriculum for real-time computer and control systems engineering. IEEE Transactions on Education 33(2), 171-178.

Harsanyi, G. and I. Lepsenyi (2000). Sensors' education and related student research projects. Proceedings of Electronic Components and Technology Conference: 1034-1041.

Isbister, K. and K. Höök et al. (2007). The sensual evaluation instrument: developing a trans-cultural self-report measure of affect. International Journal of Human-Computer Studies 65(4): 315-328.

Peyton, A. J. and J. R. Burch et al. (1996). The teaching of sensors and instrumentation to second year electronics/mechatronics students. IEE Colloquium on Sensors and Instrumentation Systems 127: 11/1-11/3.

Ramon, P. A. and G. W., John (2001). Sensors and signal conditioning. John Wiley \& Sons, INC. 2nd Edition.

Sloane, T. H. (1995).Laboratories for an undergraduate course in power electronics. IEEE Transactions on Education 38 (4): 365-369.

Wong, L. T. and K.W. Mui et al. (2005). Assessment weighting of design project- based subjects for engineering education. World Transactions on Engineering and Technology Education 4(2): 215-218. 


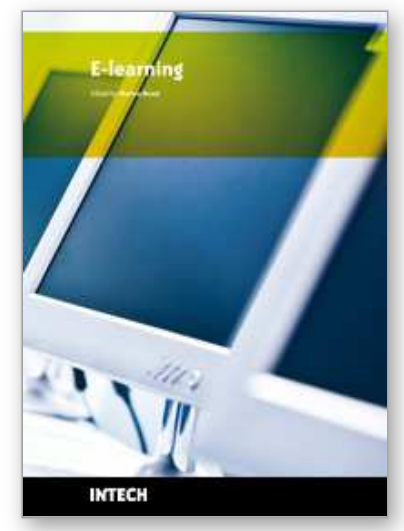

\author{
E-learning \\ Edited by Maja Jakobovic
}

ISBN 978-953-7619-95-4

Hard cover, 312 pages

Publisher InTech

Published online 01, February, 2010

Published in print edition February, 2010

E-Learning is a vast and complex research topic that poses many challenges in every aspect: educational and pedagogical strategies and techniques and the tools for achieving them; usability, accessibility and user interface design; knowledge sharing and collaborative environments; technologies, architectures, and protocols; user activity monitoring, assessment and evaluation; experiences, case studies and more. This book's authors come from all over the world; their ideas, studies, findings and experiences are a valuable contribution to enriching our knowledge in the field of eLearning. The book is divided into three sections. The first covers architectures and environments for eLearning, while the second part presents research on user interaction and technologies for building usable eLearning environments, which are the basis for realizing educational and pedagogical aims, and the final last part illustrates applications, laboratories, and experiences.

\title{
How to reference
}

In order to correctly reference this scholarly work, feel free to copy and paste the following:

Wen-Jye Shyr (2010). Development Sensor Experimental Platform Based on the Graphical Monitoring and Control System, E-learning, Maja Jakobovic (Ed.), ISBN: 978-953-7619-95-4, InTech, Available from: http://www.intechopen.com/books/e-learning/development-sensor-experimental-platform-based-on-thegraphical-monitoring-and-control-system

\section{INTECH}

open science | open minds

\section{InTech Europe}

University Campus STeP Ri

Slavka Krautzeka 83/A

51000 Rijeka, Croatia

Phone: +385 (51) 770447

Fax: +385 (51) 686166

www.intechopen.com

\section{InTech China}

Unit 405, Office Block, Hotel Equatorial Shanghai

No.65, Yan An Road (West), Shanghai, 200040, China

中国上海市延安西路65号上海国际贵都大饭店办公楼405单元

Phone: +86-21-62489820

Fax: +86-21-62489821 
(C) 2010 The Author(s). Licensee IntechOpen. This chapter is distributed under the terms of the Creative Commons Attribution-NonCommercial-ShareAlike-3.0 License, which permits use, distribution and reproduction for non-commercial purposes, provided the original is properly cited and derivative works building on this content are distributed under the same license. 